\title{
LA TERRITORIALIDAD INDÍGENA EN EL MÉXICO CONTEMPORÁNEO
}

\author{
INDIGENOUS TERRITORIALITY IN CONTEMPORARY MEXICO
}

\author{
Alicia M. Barabas ${ }^{1}$
}

\begin{abstract}
A partir de la conceptualización operativa de espacio, territorio, etnoterritorio y lugar sagrado, intentaré presentar algunos aspectos del proceso de apropiación simbólica de los territorios históricos por parte de las culturas indígenas de Oaxaca y de otras regiones de México. Está presente en el análisis la gran profundidad temporal de la convivencia indígena con sus medioambientes como piedra angular de la construcción de los etnoterritorios. A través de una breve puesta al día de la legislación nacional sobre indígenas y de la legislación agraria mexicanas, se argumenta sobre las concepciones y acciones implementadas por el estado para imponer su autoridad. La parte medular del artículo constituye un acercamiento a la construcción simbólica de los territorios indígenas y muestra al complejo de la "montaña sagrada" como espacio múltiple; de filiación étnica, de relación con las entidades extrahumanas, especialmente en la ritualidad, y de abastecimiento de todos los bienes necesarios para la vida, generalmente naturales pero en la actualidad también bienes industrializados. Desde este geosímbolo y de las nociones de cardinalidad, los pueblos indígenas identifican y significan los centros y las fronteras territoriales, tal como se advierte en la narrativa y la ritualidad.

Palabras claves: pueblos indígenas de México, etnoterritorios, apropiación simbólica, narrativa y ritualidad.
\end{abstract}

\begin{abstract}
From the operative conceptualization of space, territory, ethno-territory and sacred place, I will try to present some aspects of the process of symbolic appropriation of the historic territories by the indigenous cultures of Oaxaca and other regions of México. A keystone element in the social construction of ethno-territories is the historical coexistence of indigenous communities and their environments. Nevertheless, national legislation about indigenous peoples and agrarian legislation are in stark contrast to indigenous conceptions of territories and are prejudicial to their territorial rights. The central part of the article is the approach to the complex symbolic concept of 'sacred mountain' as a space of ethnic affiliation, of relationship with extra-human entities, especially in ritual activities, and of supply of all the goods, both natural and industrialized, necessary for human life. This 'geosymbol' and the notion of cardinality, collaborate in the indigenous identification and signification of centers and frontiers, as can be observed in the narrative and ritual dimensions.
\end{abstract}

Key words: Indigenous peoples of México, ethno-territories, symbolic appropriation, mythology and rituals.

En estas páginas intento presentar una síntesis de mi propuesta ${ }^{1}$ acerca de la que he llamado etnoterritorialidad simbólica. Al iniciar la investigación en Oaxaca $^{2}$ decidimos tomar distancia de las categorías externas constituidas por el estado, que atañen al ordenamiento territorial, como son las agrarias o las político-administrativas (municipales), y observar en cambio las categorías simbólicas indígenas, porque estas son representaciones territoriales estructuradas de acuerdo con la lógica interna propia de cada cultura, esto es, en relación con su cosmovisión y ritualidad. Lo anterior no porque las categorías generadas desde el estado no sean importantes en la construcción de la territorialidad indígena. Todo lo contrario, como lo demuestra, en un sentido, la apropiación y reelaboración indígena del municipio castellano como forma de gobierno propio, y en otro, la imposición de tipos de posesión y propiedad de las tierras indígenas, determinadas por el estado. Sin embargo, lo que buscábamos eran las concepciones y prácticas propias y profundas acerca del territorio, actualmente vigentes en las culturas indígenas.

Pronto advertimos que muchas de ellas encontraban anclaje en tiempos precoloniales y coloniales, y que continuaban reproduciéndose, no sin transformaciones, en las culturas indígenas actuales, lo que hizo necesario acudir a fuentes etnohistóricas para comprender la historicidad de la territorialidad indígena. En el mismo sentido observamos la interrelación entre las simbolizaciones acerca de los etnoterritorios y los conocimientos y prácticas relacionados con la naturaleza, que han convertido sus hábitats en territorios posibilitando la supervivencia colectiva.

\footnotetext{
1 Instituto Nacional de Antropología e Historia de México-Centro Oaxaca. Pino Suárez 715, cp. 68000, Oaxaca, México. barbar2@prodigy.net.mx
} 
Este último aspecto hizo evidente que la milenaria y equilibrada articulación naturaleza-sociedad lograda por los pueblos indígenas en sus territorios históricos, se encuentra ante nuevos peligros derivados del voraz ejercicio del capitalismo de la globalización. A la par advertimos que las formas de ordenamiento territorial impuestas por el estado son lesivas para el cumplimiento de los derechos territoriales indígenas, y que estos no son respetados a pesar de que México es signatario de convenios internacionales que los legitiman y promueven. En este complejo panorama la etnoterritorialidad se manifiesta como una categoría multifacética que se comprende mejor al ser abordada desde diferentes perspectivas; lo que intentaré realizar en las siguientes páginas, tratando en primer término la construcción simbólica de los etnoterritorios.

\section{El Territorio desde una Perspectiva Simbólica}

En la investigación desarrollada en Oaxaca intenté una lectura etnográfica de los procesos de construcción-apropiación territorial protagonizados por los grupos indígenas, valiéndome de un modelo de representación del espacio que articula las dimensiones vertical y horizontal. Estudios comparativos permiten aseverar que en numerosas culturas las orientaciones generales sobre el espacio se organizan en dimensiones horizontales y verticales, y que estas se reflejan en las cosmologías y en la configuración del espacio humano (Altman y Chemers 1980:32). La dimensión vertical con frecuencia genera la concepción de espacio tridimensional dividido en planos: arriba, medio y abajo, muchas veces comunicados entre sí a través del centro; y la dimensión horizontal, por lo común representada como cuadrángulo, pero también como círculo, organiza las orientaciones: centro y fronteras (periferia, límite). La concepción de centro, que intersecta el espacio de arriba y de abajo y desde donde se marcan fronteras, suele construirse como lugar sagrado, sea montaña o templo, a partir del cual se marcan las otras direcciones.

Para la concepción del espacio humano, retomo el concepto de territorio como espacio culturalmente construido por una sociedad a través del tiempo, y trataré de diferenciarlo del espacio, del paisaje y del lugar ${ }^{3}$.

Bien sabemos que el espacio es una noción diversamente conceptualizada por las ciencias sociales contemporáneas. Algunos lo consideran como una suerte de contenedor neutral en el que la sociedad va inscribiendo memoria, creencias y prácticas culturales (Gupta y Ferguson 1992), otros lo entienden como realidad material preexistente que tiene un valor de uso, pero que no está moldeado por el hombre (Giménez 1999), y para otros, como Massey (2005), lejos de ser neutral o congelado, el espacio se relaciona con el tiempo y por ello es dinámico. Para autores de orientación fenomenológica, como Casey (1996), el espacio tiene un sustrato de significaciones preexistentes -dado por la excepcionalidad de los fenómenos geográficos-, que son aprehendidas por la sociedad y pasan a integrar simbolizaciones posteriores. En este caso el espacio es concebido como otro actor en la construcción de significados culturales. Desde mi perspectiva el espacio no es inerte, sino un principio activo en la construcción del territorio, por lo que podría pensarse en procesos interactivos entre los usuarios y específicos espacios. Dicho de otro modo, atributos espaciales particulares, como montañas, rocas, cuevas, árboles, reciben cargas sociales de significación y las reflejan hacia la sociedad sugiriéndole una multiplicidad de símbolos, discursos y prácticas rituales. Espacio lo entiendo como el ámbito de mayor alcance, que se va constituyendo como territorio cultural con sus lugares, al ser nombrado y tejido con representaciones, concepciones y creencias de profundo contenido histórico y emocional. Por ello un dato significativo en el estudio de la territorialidad es la toponimia, que puede aludir a concepciones cosmológicas, a características del medio o a hechos remarcables ocurridos en el lugar.

El término territorio es utilizado como concepto que reúne al espacio con el colectivo, y entendido como la parte del espacio que una colectividad considera como propio (Valcuende 1999:218). El territorio puede ser así definido como espacio culturalmente construido, lo que implica que es valorizado y apropiado simbólica e instrumentalmente por la sociedad (Raffestin 1989:129), y como espacio socializado (Escalera 1999). Giménez (1999:27) apunta que es el espacio de inscripción de la cultura, pero advierte asimismo que se trata de un valor de cambio que implica relaciones de poder y negociaciones de significado. También Gupta y Ferguson (1992:11) señalaban que los significados que se crean sobre los lugares sagrados o emblemáticos del territorio cultural se negocian entre los actores o, más aún, diríamos que la conciliación de significados sobre 
esos lugares se establece mediante la articulación de los diversos discursos sociales y prácticas colectivas. De estas apreciaciones resulta que el territorio es factor de disputa y de relaciones de poder entre grupos, no solo en términos de recursos escasos y preciados por los que se compite, sino también como construcción simbólica, en la que el poder y la negociación se ejercen en relación con lo sagrado. Un ejemplo, entre otros, lo encontramos en la región mixe de Oaxaca en la cual existe fuerte disputa por el uso de los lugares sagrados (cerros) entre las comunidades tradicionales y las evangelizadas en la Teología India. Tal vez sea oportuno destacar que, más allá de las diferencias de enfoque, la mayoría de los actuales estudiosos del tema en la antropología coincide en conceptualizar el territorio como un sistema de símbolos, una manera de clasificar, cualificar y habitar el espacio, que sigue pautas y crea códigos transmisibles culturalmente.

En relación con el paisaje algunos autores suelen privilegiar hoy en día este concepto por sobre el de espacio o territorio, adjudicándole un carácter concreto, vivencial y próximo. Así, el paisaje es identificado como típico de un área y del pueblo que la habita, e igualmente los habitantes se identifican con ciertos paisajes como emblemas de su identidad y de su territorio; tal como señala Giménez (2001) el paisaje se convierte en metonimia del territorio.

Desde mi perspectiva, el concepto territorio se refiere a los espacios geográficos culturalmente modelados, pero no solo los inmediatos a la percepción, que remiten al paisaje, sino los de mayor amplitud, que son reconocidos en términos de límites y fronteras etnoculturales. Esto es, la noción de territorio como un espacio propio bordeado de fronteras, por porosas que estas puedan ser. Es el caso, como veremos más adelante, de varias culturas de Oaxaca que reconocen cerros específicos como hitos que marcan sus fronteras internas o subregionales y sus fronteras interétnicas. Asimismo, algunas de las peregrinaciones muestran -o insinúan- las fronteras de antiguos centros ceremoniales aglutinadores, de territorios de viejos señoríos; memoria histórico-territorial que hoy es refrendada por comunidades afines que recrean en ellas lazos simbólicos supracomunitarios. Es así que la mayoría de los lugares sagrados o significativos persisten en el tiempo y llegan a constituirse en emblemas territoriales e identitarios.

Una cuestión que se relaciona estrechamente con la discusión anterior es que territorio resulta ser un término con connotaciones geopolíticas, que da por aceptada la centralidad de la cuestión de los derechos territoriales de los pueblos indígenas. En este sentido, la importancia de los estudios sobre territorialidad simbólica no solo radica en el conocimiento etnológico que proporcionan sobre el sistema de representaciones espaciales de los pueblos indígenas sino en que se constituyen como un cuerpo de datos para la delimitación de etnoterritorios. Al respecto existe jurisprudencia en América Latina y en otros países del mundo sobre la aceptación legal del "conocimiento local" para la delimitación de territorios indígenas ${ }^{4}$. La naturaleza o el espacio pueden ser concebidos sin límites, pero los territorios habitados y apropiados sí los tienen, tal como dejan ver históricamente en México los códices, mapas, lienzos y títulos primordiales.

Vale detenerse un momento en una de las herramientas más importantes para el proceso de demarcaciones territoriales: los mapas participativos. El mapeo de tierras indígenas es un fenómeno reciente que comenzó en Canadá y Alaska hacia 1960, y en otras áreas, como las regiones tropicales de América Latina, África y Asia, hacia $1990^{5}$. Chapin et al. (2005:169) realizaron una exhaustiva revisión de la historia del mapeo indígena y, en particular, de las "dificultosas mezclas de acercamientos comunitarios participativos con el uso de tecnología satelital". Desde la mitad de 1990 y en la actualidad la tecnología ha dominado tanto el fenómeno que se le llama participatory GIS (Abbot et al. 1998). Estudiosos del tema señalan que la tecnología del GIS puede encajonar y manipular el conocimiento tradicional, y que cuando es aplicada en campos interculturales "es esencialmente una herramienta para la asimilación epistemológica... un intento más de occidente para subsumir y destruir las culturas indígenas" (Johnson 1997:4). De acuerdo con Carver (2001), el GIS trabaja en contra de la participación y el empoderamiento.

Esta útil herramienta, o keystone activity como llama Herlinhy (2003) a los "mapas participativos", puede ser un elemento valioso cuando es utilizada por los propios grupos indígenas para los fines de legalizar dentro de la estructura del Estado nacional sus territorios ancestrales, como en los casos ye'kuana y hoti (Barabas 2006), pero también es un arma peligrosa cuando está orientada por intereses ajenos a los pueblos indígenas, que pueden ser perjudiciales aunque aparezcan legalizados por el Estado y el mundo académico. Tal es el caso del proyecto 
"México Indígena" de la Bowman Expedition llevado a cabo desde 2002 por geógrafos de la American Geographical Society, la Universidad de Kansas, en Estados Unidos, la Universidad de Carleton, en Canadá, y diversas instituciones de gobierno y académicas mexicanas, con el propósito explícito de analizar la recepción del programa PROCEDE (Programa de Certificación de Derechos Ejidales y Titulación de Solares Urbanos) entre grupos indígenas de la Huasteca potosina, Oaxaca y Chihuahua, y elaborar mapas de sus tierras con metodología participativa. Durante enero y febrero de 2009, la multiorganización indígena zapoteca UNOSJO (Unión de Organizaciones de la Sierra Juárez de Oaxaca) denunció al proyecto "México Indígena" por acciones de geopiratería en seis comunidades zapotecas. Se sustentaba en que nunca habían sido informados de la procedencia de los fondos de ese proyecto: la Foreign Militar Studies Office del ejército de Estados Unidos, que tampoco se les había dicho que los mapas resultantes así como otros informes eran enviados mensualmente a esa oficina del ejército, y que nunca se les había mencionado su relación con el programa PROCEDE, que no es aceptado en sus comunidades. Por estos motivos prohibieron la entrada del proyecto y su gente a las comunidades zapotecas (UNOSJO 2009).

Regresando a nuestro tema central, los territorios culturales o simbólicos a los que nos referimos son los que habitan los grupos etnolingüísticos, de allí que les llame etnoterritorios ${ }^{6}$, entendiéndolos como el territorio histórico, cultural e identitario que cada grupo reconoce como propio, ya que en él no solo encuentra habitación, sustento y reproducción como grupo, sino también oportunidad de reproducir cultura y prácticas sociales a través del tiempo. El etnoterritorio remite al origen y la filiación del grupo en el Lugar y los niveles de autoreconocimiento pueden ser étnicos, regionales, subregionales o comunales. Esto es, que se construyen etnoterritorios locales, de nivel comunitario, que es la forma actualmente más reconocida, así como globales, que pueden ser subregionales o abarcar todo un grupo etnolingüístico, lo que supone cierto nivel de abstracción, ya que no se trata de territorios de lo cotidiano.

Tanto los territorios locales como los globales tienen puntos o hitos geográfico-simbólicos especialmente significativos para los usuarios, que generalmente son considerados sagrados. Estos puntos referenciales son emblemáticos y pueden ser identificados como lugares; centros a partir de los cuales se identifican las fronteras comunales, subregionales y étnicas. Entre las culturas indígenas de Oaxaca y de casi todo México esos centros o lugares simbólicos de la territorialidad han sido y son: el cerro, la cueva y la fuente de agua.

Al pensar el territorio como culturalmente construido y apropiado, debe reconocerse al lugar como una noción fundamental. Se trata de una categoría privilegiada por los fenomenólogos estudiosos de la territorialidad porque se circunscribe al ámbito de la vivencia individual e interpersonal. Algunos de sus defensores dicen que el lugar sintetiza el encuentro entre tiempo y espacio (Casey 1996:36), otros que el espacio, al semantizarse, se construye socialmente como lugar (Gupta y Ferguson 1992:11). Debemos convenir en que para los actores sociales, si bien se reconocen territorios abstractos, los que cuentan afectivamente son los lugares cercanos a la experiencia; ricos en algún recurso vital, o marcados como lugares poderosos por las gestas de los héroes míticos y los rituales que los cargan de significados. Hemos comprobado, por medio de los relatos sobre los cerros, cuevas y manantiales, que los lugares sagrados suelen tener unidades interiores de significado manifiestas en las marcas o huellas que han dejado los héroes culturales (o los santos) en su camino fundador del territorio: huellas del pie, del caballo, del malacate, de los testículos, la huella sinuosa de la culebra, que facilitan su identificación colectiva y muchas veces dan nombre al lugar. Los lugares -y las marcas- están asociados a eventos míticos y rituales: en ellos viven, o ellos son, y se manifiestan las entidades territoriales extrahumanas, con voluntad y figura ${ }^{7}$, conocidas como dueños de lugar (dueño del cerro, de la tierra, del agua, del viento, etc.), y los héroes, o los reyes fundadores, que viajaron de sitio en sitio y fueron estableciendo lugares y marcas emblemáticos del etnoterritorio.

A los lugares sagrados de reconocimiento y convocatoria colectivos, que se convierten en centros rituales de los etnoterritorios, les he llamado santuarios $^{8}$. Los santuarios son lugares sagrados complejos y polifacéticos que no solo marcan emblemáticamente el territorio donde se ubican, sino que son factores principales de interacción social intra e interétnica. Para que exista un santuario, señala Velasco Toro (1993), deben darse ciertas características significativas que permitan su conversión de sitio común en lugar sagrado. Tiene que ocurrir un hecho maravilloso que legitime su 
carácter numinoso y dé origen al mito fundacional y al culto posterior. Es entonces cuando el lugar adquiere sus poderes mágicos, curativos, protectores, milagrosos, y se convierte en santuario. Puede hacerse una distinción operativa ${ }^{9}$ entre santuarios naturales y santuarios construidos, con base en las características externas del santuario, y el control (o ausencia de él) de la iglesia sobre las calendarizaciones y las devociones. Los santuarios naturales (el cerro, el árbol, el manantial, la cueva, formaciones rocosas peculiares, etc.) no tienen templos, cuando más cruces o pequeños oratorios, y no son conocidos o aceptados por la iglesia, en tanto que los santuarios construidos cuentan con templos e iglesias, forman parte de la práctica católica popular y son manejados por la iglesia; no obstante, ambos brindan a los fieles las condiciones para construir referencias territoriales culturales.

\section{Etnoterritorios Simbólicos en Oaxaca}

Retomando para las culturas de Oaxaca el modelo de representación del espacio en las dimensiones verticales y horizontales que he mencionado páginas atrás, observamos que nos permite entender la dinámica de construcción-apropiación territorial.
En cuanto a la dimensión vertical, los relatos y rituales dejan ver la persistencia de las concepciones de raíz mesoamericana acerca del quincunce con el centro axis mundi, sostenido en las cuatro esquinas y estratificado en tres planos: supramundo, mundo e inframundo, integrados el primero y el último por variable número de niveles o pisos. En la actualidad algunos de los pueblos indígenas de Oaxaca, como los mazatecos y los mixes, tienen una cosmovisión más detallada de su panteón de deidades celestes, en tanto que para otros se halla más interferida y homogeneizada con el panteón de santos cristianos. En cambio, las concepciones sobre el inframundo son variadas y complejas en todos los pueblos, aunque en casi todos ellos encontramos un cuerpo común de creencias básicas: el acceso por las cuevas de la montaña, un primer nivel en el que moran los dueños del cerro, pleno de abundancia y bienes, y un nivel de abajo que es el mundo de los muertos, símil del de los vivos, al que el espíritu del difunto llega después de atravesar por un número variable de niveles de obstáculos (Figuras 1 y 2).

El mundo del medio se expresa en el territorio y sus medioambientes diversos. La gente dice que el monte y el cerro son el territorio sagrado de los Dueños, y este es "delicado" y "pesado", aludiendo

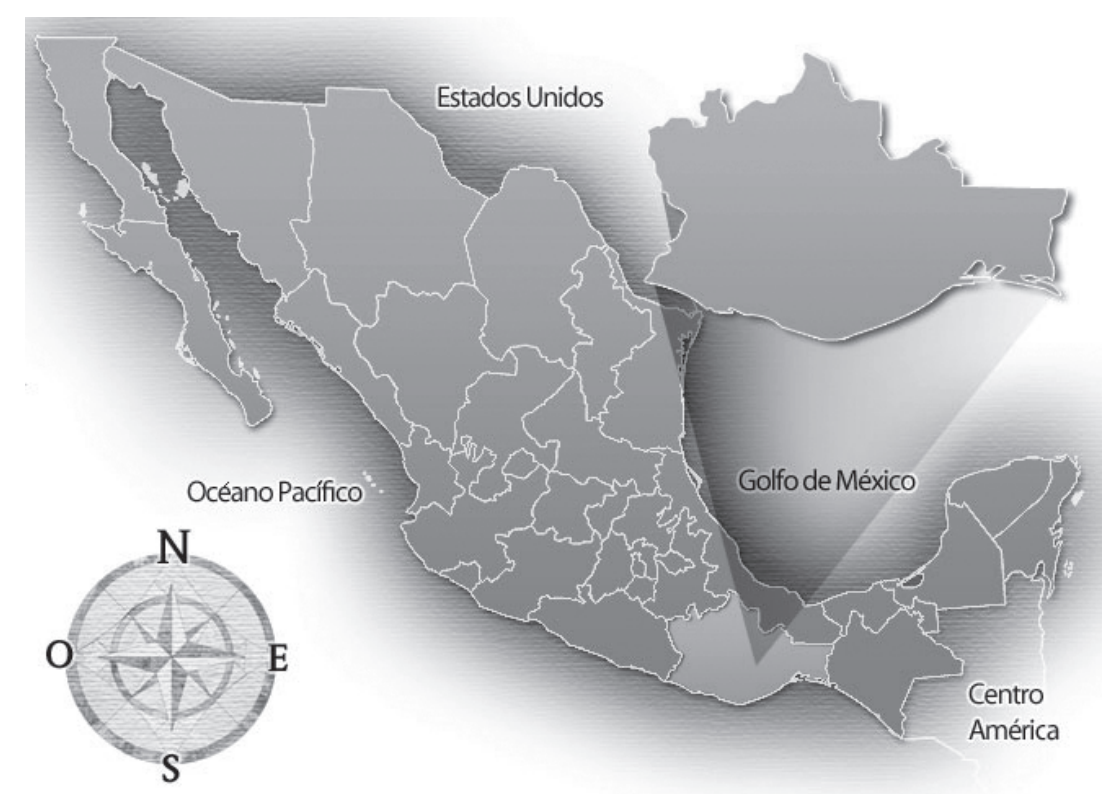

Figura 1. Mapa de los Estados Unidos de México, con la proyección del estado de Oaxaca. Fuente: Instituto Nacional de Geografía, Estadística e Informática (INEGI), México, 2013. Map of United States of Mexico with Oaxaca State.

Source: National Institute of Geography, Statistics and Information (INEGI), Mexico, 2013. 


\section{GRUPOS ETNOLINGÜÍSTICOS DE OAXACA}

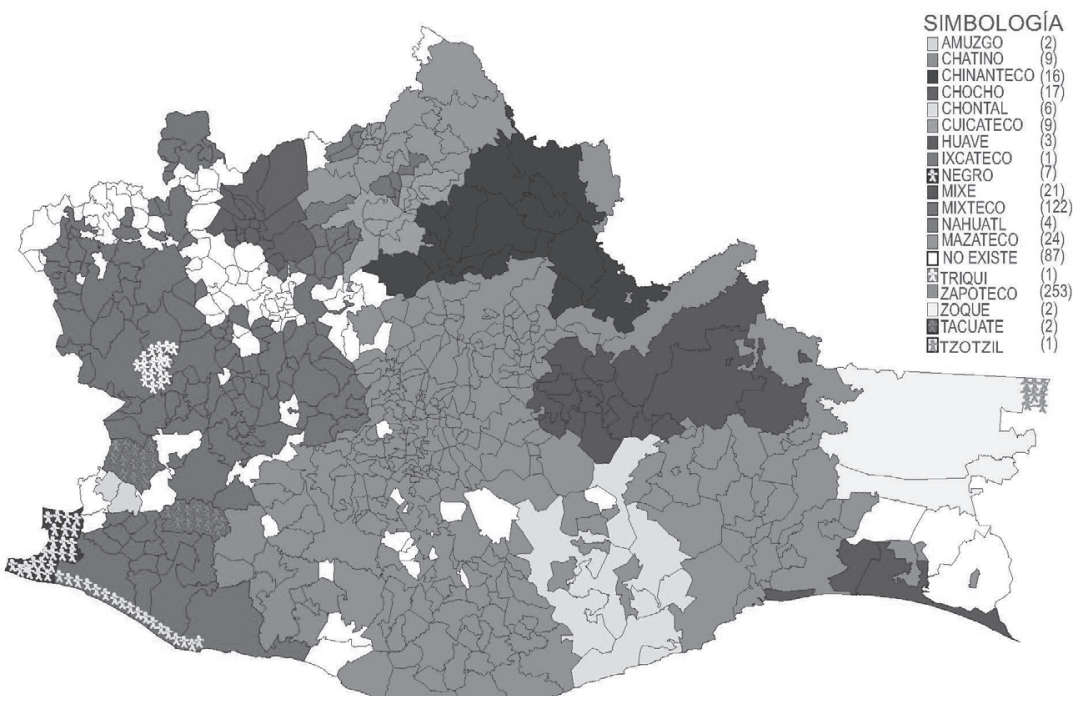

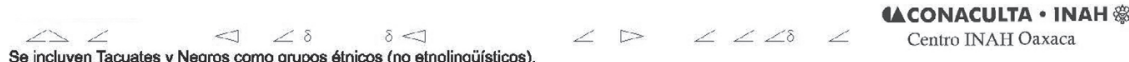

Figura 2. Mapa de los grupos etnolingüísticos del estado de Oaxaca.

Fuente: Centro INAH Oaxaca, México, 1999-2002.

Map of the Ethno-linguistic Groups of Oaxaca State.

Source: Oaxaca National Institute of Anthropology and History (INAH) Centre, Mexico, 1999-2002.

a su cualidad heterogénea respecto del tiempo y espacio ordinarios. Peligroso, por el carácter irritable de las entidades anímicas territoriales, en el cual debe evitarse toda transgresión moral a fin de evitar el castigo presentado como enfermedad.

Los lugares sagrados principales, que actúan como centros simbólicos de la etnoterritorialidad, son generalmente santuarios naturales que forman parte de lo que he llamado complejo cerro, que integra referentes naturales como la montaña, las cuevas, las fuentes de agua y algunos árboles, y referentes etnoculturales. A lo largo de la historia ha sido -y es hasta ahora- símbolo emblemático del pueblo que lo tiene como referente, lugar de abundancia y dones, morada de los ancestros tutelares y sus animales compañeros, los nahuales, y de los santos patronos; todos concebidos como protectores, donadores y defensores de los límites territoriales. Los cerros por lo común son señalados como parejas de diferente género, aunque se ubiquen muy separados uno de otro, y los habitantes de cada pueblo suelen construir una relación filial con el más alto o peculiar de su entorno geográfico. En muchos casos el cerro emblemático es concebido como la entrada al inframundo y también puede ser visto como cerro de "mantenimientos", esto es, como reservorio de todo tipo de riquezas naturales $\mathrm{y}$, en la actualidad, también oro y dinero (Barabas 2003b).

Además de los cerros, también las gestas territoriales de los héroes y los reyes míticos que se narran en los relatos fundacionales, marcan centros de los etnoterritorios. Fundar implica nombrar un espacio, trazar límites orientados desde un centro, en este caso cardinalmente, y hacer de un espacio salvaje un espacio humanizado mediante la alianza con las entidades territoriales sagradas. Los relatos de fundación que simbolizan la radicación de un pueblo en un territorio particular que le es concedido como propio, son paradigmáticos porque constituyen el acto primigenio de creación del territorio por parte de una entidad sagrada que elige, marca, nombra y sacraliza el Lugar y al Pueblo que ha de habitarlo. Estos relatos son parte sustancial del conocimiento sobre el etnoterritorio, en particular los de los antepasados ilustres conocidos como reyes, que son al mismo tiempo héroes culturales -a veces los gemelos Sol y Luna-, que le legaron el 
territorio ancestral a la gente marcándolo con sus huellas y creando cerros, planicies, hondonadas, manantiales y diversos bienes culturales (el arco y las flechas, el cultivo, entre otros) (Barabas 2003b).

Otros eventos fundadores de centros-santuarios, tanto naturales como construidos, son los relatos aparicionistas de los ejemplares católicos -vírgenes y santos-, que dejan mensajes, huellas de su presencia en la geografía, y eligen, trasladándose de un sitio a otro, el lugar donde se fundará su templo y, con él, el pueblo del que serán protectores. Esta narrativa, conocida para la época colonial y contemporánea, es fundacional y suele dar origen a nuevos pueblos, cuyos santuarios pueden tener amplia convocatoria. Mucho puede decirse acerca de los significados simbólicos, sociales, políticos y geopolíticos de las apariciones milagrosas (Barabas 1997, 2006); por el momento solo quiero resaltar que los santos aparecidos, muchos de los cuales se convierten en Santos Patronos de los pueblos, suelen estar ligados al medio ambiente donde aparecen (fuentes de agua, cuevas, cerros, árboles) y, en ocasiones, son identificados con el dueño del lugar y su nahual la culebra. Por otra parte, retoman el papel fundador y protector del territorio y del pueblo al que eligen, que antes desempeñaban, y aún desempeñan, los ancestros y las entidades territoriales sagradas; siendo entonces fundamentales en la construcción de identidades y territorios étnicos (Barabas 2003b, 2006).

Pero los cerros no solo marcan centros, al mismo tiempo algunos de esos cerros emblemáticos marcan fronteras entre subregiones de un grupo, como muestra el caso de la mazateca con los tres cerros; Chikon Tokosho, San Martín Caballero y Rabón, que identifican a las subregiones alta, media y baja de la región mazateca. En otros casos, marcan fronteras entre grupos etnolingüísticos, como el cerro Mujer entre la chinantla baja y la región cuicateca, o el cerro Pájaro entre la región chatina y la mixteca de la costa (Barabas 2003b). Lo que quiero destacar aquí es que los lugares sagrados configuran una geografía simbólica y permiten trazar mapas de la territorialidad de cada grupo étnico. Los etnoterritorios tienen referentes geográficos culturalmente significativos que sirven como fronteras, pero estas son ámbitos de interacción y los usuarios pueden traspasarlas y modificarlas. No obstante en las culturas de Oaxaca las fronteras entre grupos etnolingüísticos, aun las simbólicas, tienen densidad y son conocidas por las diferentes comunidades (Figura 3).

La casuística etnográfica permite señalar que en el nivel simbólico los pueblos indígenas conciben las fronteras entre etnoterritorios como marcadas y

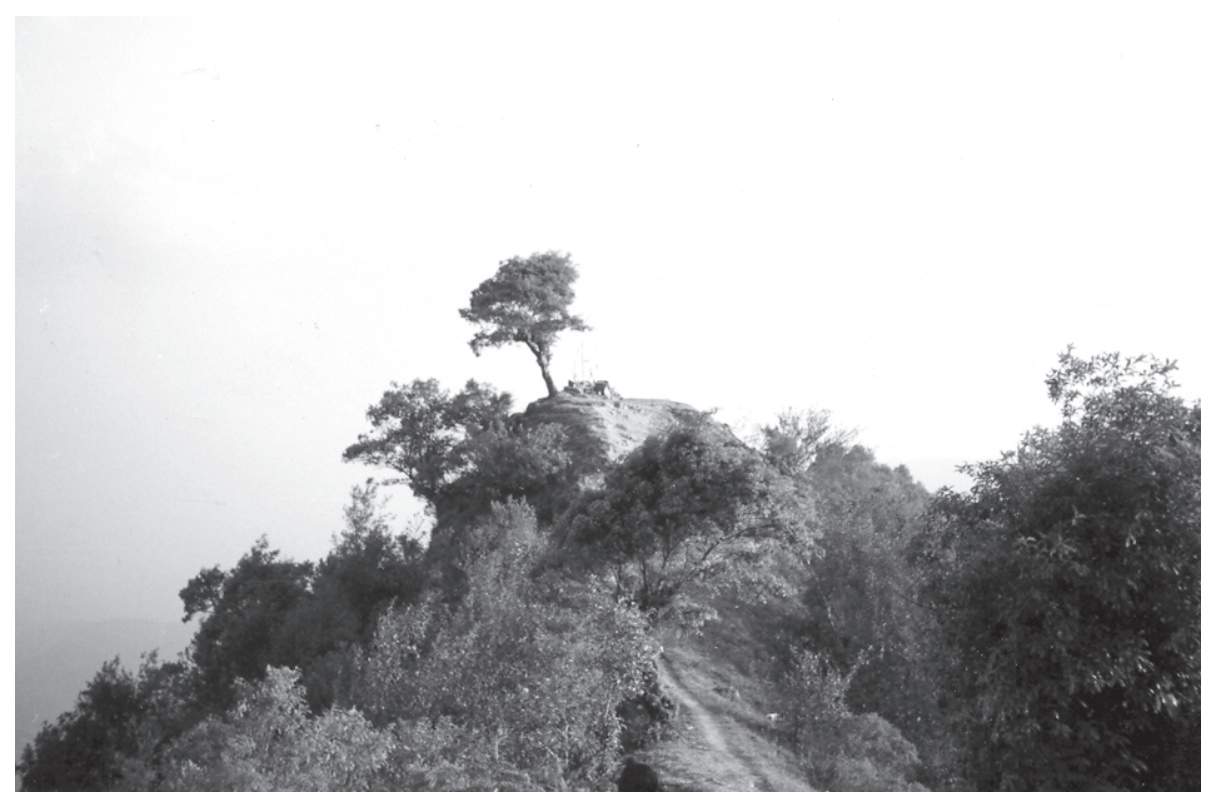

Figura 3. Cerro Chikon Tokosho, lugar sagrado emblemático del pueblo indígena mazateco del estado de Oaxaca. Fotografía: Lidia Manrique Rosado, 2005.

Chikon Tokosho Mountain, paradigmatic sacred place of the Mazatec Indian people of Oaxaca State.

Photograph: Lidia Manrique Rosado, 2005. 
protegidas por las entidades sagradas. Son fronteras, a partir de un centro, las cuatro esquinas del cosmos, del etnoterritorio, del monte, de la milpa, del pueblo y de la casa-solar. En el nivel local, el espacio del monte y de la milpa, cercanos a los límites con lo poblado pero en zona de frontera, son "peligrosos" y deben guardarse actitudes precautorias, porque en ellos aparecen los Dueños de los Lugares, sus nahuales o tonas (alter ego animal de cada persona), y diversas entidades anímicas territoriales. Son sin embargo territorios cotidianos que se ubican cardinalmente y mediante los accidentes geográficos significativos y se marcan con oratorios, cruces y ofrendas.

En el ámbito de la comunidad, los límites de la casa y del solar suelen marcarse con cruces y mediante las ofrendas y partes corporales (cordón umbilical, placenta) enterradas en las cuatro esquinas y en el centro. En el territorio del barrio y de la comunidad los límites son señalados con cruces, mojoneras y oratorios, y refrendados durante las procesiones, que recuerdan centros, márgenes y límites interiores (domésticos, barriales, mitades, comunitarios). En ocasiones, las procesiones barriales refrendan no solo el oratorio o capilla que es el centro, sino también la existencia y los límites de las viviendas y los solares familiares. Desde esta perspectiva las procesiones constituyen una forma de recordar, refrendar y resacralizar los límites internos y externos de la comunidad. Al mismo tiempo, son ritos de "cerramiento" de las fronteras de la comunidad o del municipio que, en la concepción local, impiden la "entrada" de fuerzas adversas. Esto es, que las procesiones podrían ser entendidas como rituales de reconstitución comunitaria que invocan la protección de lo sagrado y, al mismo tiempo, constituyen recursos mnemónicos colectivos acerca de los límites del pueblo y sus lugares más sagrados, que se renuevan y remarcan periódicamente legitimando la posesión de ese espacio por ese pueblo y recordando al mismo tiempo las fronteras con los pueblos vecinos.

Las fronteras simbólicas comunales, subregionales o étnicas son frecuentemente marcadas a partir de cerros considerados como lugares sagrados, pero también son señaladas y reafirmadas por los chamanes en sus periódicas disputas celestes. En este caso, lo que nos permite detectar fronteras a nivel simbólico es un conjunto de relatos a los que puede llamarse de "vigilancia de fronteras", que se registran entre todos los grupos indígenas de Oaxaca.
Narran disputas fronterizas entre comunidades del mismo pueblo indígena, o entre diferentes pueblos, exponiendo relaciones contrastivas entre ellos y la competencia por bienes y posiciones sociales. Se expresan como rivalidades entre los nahuales o entidades anímicas compañeras de los chamanes o de los Dueños de Lugar de cada pueblo enfrentado, y los conflictos tienen lugar en un plano no ordinario del mundo, pero se manifiestan en este mundo como tormentas eléctricas porque los nahuales en disputa suelen ser rayos, centellas, truenos y ventarrones. Tienen repercusiones sobre los bienes del territorio comunal, como la destrucción de las torres de la iglesia, la desaparición de la campana o la pérdida de algún recurso natural. Las acciones de las entidades anímicas, en la forma de meteoros o animales salvajes, están encaminadas a cuidar los recursos del territorio y vigilar que no se violen los límites de los pueblos a los que protegen, por lo que no dejan pasar extraños, enfermedades o nahuales de otros pueblos. Muchos de esos relatos narran la superioridad del pueblo narrador frente a las comunidades en competencia, otros muestran sus pérdidas. Puede decirse que en las fronteras, ya sean las comunales o las étnicas, la manifestación territorial de la sacralidad opera como potencia de "cerramiento" o barrera que protege al endogrupo y lo separa de los otros.

Muchos relatos hablan de la pérdida de agua y de las riquezas materiales asociadas con ella. Esta narrativa surge de la concepción sobre lugares de grandes riquezas naturales relacionados con un tiempo anterior imaginado como paraíso de abundancia, que deja lugar a la pobreza de la vida actual, por abandono de las entidades sagradas dueñas de esas riquezas. No pocas veces la responsabilidad de ese abandono suele ser atribuida a los mismos indígenas, que dejan de creer y de cuidar a las entidades del territorio. Lo que expresan los relatos es el conflicto con las entidades territoriales, no ajeno al catolicismo y a las religiones protestantes, que conduce al despojo de los bienes del grupo: errores, ofensas, falta de "pago" (ofrenda), desatención o falta de respeto con los númenes, implican quiebras graves de la ética del don, ya que se rompe la relación de reciprocidad con lo sagrado (Barabas $2003 c)^{10}$. Los númenes agraviados deciden llevarse a otra parte las riquezas que tenían en el cerro y entregárselas a otra comunidad u otro grupo. Esas riquezas suelen ser naturales: agua, lluvia, semillas, milpas, peces, animales salvajes, ganado, frutos; 
pero con frecuencia son también -o en lugar detesoros en joyas y dinero. A estos relatos que marcan territorialidad de frontera, comunal o étnica, los llamamos mitos "de privación" porque implican la pérdida de bienes de una comunidad en favor de comunidades vecinas del mismo grupo, de comunidades de otros grupos o de pueblos mestizos, simbolizando el cambio de una mejor condición y medioambiente que existían en el tiempo inicial, y explicando la actual situación de carencias y deterioro ambiental. De esta forma, constituyen una expresión simbólica de las relaciones interétnicas desiguales y de los conflictos intercomunitarios, no solo entre indios y blancos, sino también entre distintos grupos indígenas.

Aunque no es usual que las procesiones y las peregrinaciones sean tratadas como datos de la territorialidad, se han demostrado como una fuente fundamental de información sobre diferentes formas de apropiación del espacio. Mientras que las procesiones recuerdan y refrendan centros y fronteras al interior de las comunidades y en el territorio comunal ${ }^{11}$, las peregrinaciones marcan territorios étnicos, históricos o de culto, estableciendo circuitos, o bien establecen rumbos y caminos sagrados hacia los santuarios, dentro de regiones devocionales. Hemos registrado diferentes tipos de peregrinaciones, no obstante puede decirse que las lejanas y dirigidas a santuarios extrarregionales construyen lo que podríamos llamar "territorios de peregrinación"; caminos sagrados por donde se transita cada año estableciendo las mismas pautas y marcas rituales en dicho territorio (Barabas 2003b). En cambio las peregrinaciones que reúnen a un grupo determinado de comunidades vecinas en torno de la celebración de uno o más santos que peregrinan entre ellas, constituyen actos estrechamente ligados a la reproducción simbólica de un espacio territorial común que se quiere refrendar, valiéndose de la memoria histórica y del ritual. El paso de estos santos renueva, recuerda, vínculos históricos y marca un territorio devocional compartido más amplio que los comunitarios ${ }^{12}$.

Parece importante concluir esta sección diciendo que al identificar centros y fronteras allí donde los santuarios, los mitos y los rituales nos los señalan, podemos contribuir a trazar mapas de la geografía simbólica de los etnoterritorios. Aun cuando la construcción de la territorialidad es un proceso dinámico, los lugares sagrados emblemáticos muestran una gran profundidad temporal y constituyen fenómenos-guía para la delimitación de los espacios culturalmente significativos, que son los de la memoria y del territorio vivido.

\section{La Profundidad Histórica de la Territorialidad Indígena}

La etnografía de diversos rituales, agrarios y terapéuticos entre otros, así como la recopilación de numerosa narrativa de diversa índole (Barabas 2003 a, b y c, 2004, 2006), proporcionaron evidencia de singular importancia para confirmar la reproducción milenaria, hasta el presente, de conceptos fundamentales relacionados con la configuración de la territorialidad, que los cronistas primero y los historiadores después, describieron para los pueblos indígenas prehispánicos y coloniales.

Bien sabemos que aunque las culturas indígenas, como toda cultura, son dinámicas, y las sociedades elaboran reconfiguraciones a lo largo de la historia en relación con distintos procesos sociopolíticos, económicos e ideológicos, es convincente la propuesta de que algunas concepciones, como las de tiempo y espacio, persisten a lo largo de la historia profunda y se reproducen estructuralmente, aunque los referentes concretos puedan ir variando. Como categorías culturales estructurantes y persistentes, que devienen de los tiempos precoloniales, pueden integrarse a lo que López Austin (1994) llama núcleo duro mesoamericano. Este núcleo duro, por su densidad significativa, se reproduce en las culturas indígenas contemporáneas en diversas concepciones y prácticas sociales. Entre ellas destacan dos, profundamente interrelacionadas, que se encuentran muy vigentes: la montaña sagrada y la cardinalidad en la representación del cosmos.

Estudios etnohistóricos realizados en la región mixteca de Oaxaca (Jansen 1998) señalan que en la época prehispánica el nombramiento de los cinco lugares cardinales sagrados se realizaba en el contexto de ceremonias conmemorativas de la fundación de señoríos, en las que el sacerdote remarcaba los linderos del territorio mixteco delimitado por los ancestros en la época primordial, a partir de los cerros emblemáticos. La concepción mesoamericana de que los grandes ancestros se transformaban a su muerte en montañas, apoya la idea de que al invocar a los antepasados se invocaba también a los lugares de los dueños del cerro y sus animales compañeros, los nahuales. La concepción de que los ancestros son los dueños protectores y fundadores 
de un pueblo en un territorio está vigente en los pueblos indígenas actuales, y se relaciona con los atributos y funciones otorgados más tarde también a los Santos Patronos.

El territorio del señorío se marcaba en los códices mediante el símbolo del cerro-agua, o grupo de cerros emblemáticos, conocido en náhuatl como altépetl, tal como después se hizo -al menos por un tiempo- en los lienzos y mapas coloniales que graficaban el territorio de la República de Indios. Lo que interesa enfatizar es que la deidad tutelar del altépetl daba origen al linaje con su identidad, lengua y costumbres, le entregaba un territorio marcado y delimitado, lo protegía de diversos males y le brindaba lo necesario para el sustento y la reproducción como grupo. Vale destacar que la categoría socioterritorial altépetl ha sido identificada entre otros grupos indígenas de México y de Oaxaca con sus propios nombres. Para la época colonial el historiador Carmagnani (1988:47) advierte que el símbolo polifónico cerro-cueva estaba presente en diversos documentos y era el centro de la cosmovisión y de la territorialización comunal y étnica, en particular entre zapotecos y mixtecos. Podemos concluir que si bien las fronteras entre las ciudades o los señoríos eran probablemente difusas, por ser ámbitos muchas veces interétnicos y cambiantes, es posible que las sociedades nativas de Oaxaca hayan construido desde épocas tempranas sus territorios culturales a partir de estas concepciones sobre el cerro, la cueva y el agua, insertos en nociones de cardinalidad.

Ha sido documentado para los nahuas prehispánicos (López Austin y López Luján 2009) que la montaña era concebida como hueca, un sitio de origen de la riqueza vegetal, y la cueva era la entrada al mundo de abajo; un mundo de agua, abundancia, vegetación, plantas, frutos, animales y peces. Ese primer nivel del inframundo (tlalocan) era el dominio del dueño de la montaña o dueño del cerro, como se le llama hoy. En el piso más bajo se ubicaba el mundo de los muertos (mictlán). Entre los poderes del interior de la montaña estaban los de germinación y crecimiento que, aunados a los de donación de bienes, orientaron a diferentes autores a llamarlo "montaña de mantenimientos" o "bastimentos". Si traigo a colación las concepciones históricas sobre los cerros, sus riquezas y su estratificación interior, es porque, como ya se ha mostrado, estas se reproducen en casi todos los pueblos indígenas actuales de Oaxaca (Barabas 2006).
La representación del cosmos que, según ha sido ya señalado (López Austin 1984), se replica en la naturaleza, la sociedad, el cuerpo y la vivienda, marca las cuatro orientaciones establecidas desde el centro o axis mundi. Estas son las esquinas donde se ubican los númenes sostenes del mundo, a las que llamamos puntos cardinales. Las culturas indígenas otorgan poderes y cualidades diferenciales a cada punto cardinal, unos positivos otros negativos, pero todos invocados. Hacia las cuatro esquinas del mundo desde el centro, se dirige toda plegaria y acción ritual, por igual en el espacio del monte, el pueblo y la casa, para todo "pedido de permiso" y todo "pago" por lo solicitado. Cada acto ritual se dirige primero y por último a las cuatro esquinas, a los cuatros dueños, a los cuatro vientos. Por ello podemos decir que la cardinalidad, tanto hoy como ayer, es otra de las categorías del núcleo duro, nodales en la estructuración del espacio y de la ubicación de las personas en él; es una concepción persistente en la cosmovisión de los grupos indígenas de Oaxaca y de muchas otras regiones indígenas del ámbito mesoamericano.

\section{Territorio: Medioambientes y Sociedad en la Historia}

Aunque nuestra búsqueda estuvo centrada en la apropiación simbólica del territorio, no sería posible no mencionar, ya que ambas están profundamente interrelacionadas, la apropiación medioambiental que ha construido la territorialidad indígena; proceso que tiene una gran profundidad histórica. En Oaxaca, la ciudad zapoteca de Monte Albán fue fundada en el año 400 antes de nuestra era, y para esa época -precedida de las aldeas tempranas- se han documentado sistemas de riego y diversas formas de aprovechamiento de humedad, además de numerosas plantas domesticadas y cultivadas con adaptaciones convenientes a los diversos suelos, altitudes y precipitaciones (Winter 1985). La convivencia milenaria de los pueblos indígenas de Oaxaca con sus variados medioambientes es precisamente lo que ha convertido a la naturaleza en territorios.

Estamos entonces partiendo de la premisa de que los etnoterritorios son paisajes culturalmente construidos por las sociedades, que muestran la diversidad de las formas de relación de cada sociedad con la naturaleza. Desde la antropología se les ha llamado etnoconocimientos a los conceptos de los 
pueblos indígenas que regulan la práctica sobre el uso y manejo tradicional del medioambiente y sus recursos naturales. Aunque abarcan también la terapéutica y otros saberes, el uso más frecuente refiere a la articulación histórica entre cultura y medioambiente local, esto es el territorio que un pueblo habita, conoce y maneja a través del tiempo. Son conocimientos transmitidos de generación en generación por la vía oral y por la práctica. Son dinámicos, ya que se encuentran en constante proceso de transformación, pero se sustentan en la observación y en prácticas milenarias entretejidas con la cosmovisión y con una arraigada estructura de valores, creencias y rituales y, por ello, forman parte del núcleo duro de la civilización mesoamericana.

Los etnoconocimientos se manifiestan en formas o estilos de vida que tanto las ciencias sociales como las biológicas han advertido que son fundamentales para la conservación y utilización sostenible de la diversidad biológica. Para Toledo y Bassols (2008:41), la biodiversidad está constituida de plantas y animales silvestres, pero también de los organismos domesticados que constituyen el aporte del hombre a la diversidad natural. Las adaptaciones produjeron una gama de variaciones, y son el producto de un fino conocimiento ecológico de las condiciones locales: microclimas, variedades de suelo y relieve, ciclos climáticos, de germinación, de cosecha, etc. En el conocimiento tradicional existen saberes detallados de carácter taxonómico sobre el paso del sol y de la luna, las constelaciones, las nubes, los vientos, los tipos de minerales y sobre los procesos geofísicos, biológicos y ecológicos. El número de taxa botánicos empleados por las culturas indígenas de México para designar los tipos de plantas alcanza entre mil y dos mil nombres, y el de animales 600 nombres. Por ejemplo, los huaves de Oaxaca en una estrecha franja tropical costera, y a pesar de ser pescadores, identifican 18 agrohábitats de acuerdo con la topografía y el suelo y reconocen 11 taxa de suelos agrícolas según variados criterios (Toledo y Bassols 2008:88).

En Oaxaca los tipos de medioambientes existentes en diferentes pisos ecológicos ubicados a cortas distancias, las barreras naturales que son las montañas, y el ciclo anual de lluvias, orientaron a los pueblos indígenas a desarrollar estrategias agrícolas basadas en la diversidad biológica. Por ello, la actual etnoecología concluye que los indígenas utilizan la diversidad como una estrategia y un medio productivo, haciendo un uso múltiple de los ecosistemas
(Toledo et al. 1978) y creando paisajes bioculturales (Boege 2008); y la arqueología nos dice que así lo han venido haciendo desde la temprana época prehispánica (Winter 1985). Los etnoconocimientos sobre el medioambiente se expresan también a través de diferentes creaciones culturales y rituales. Entre las más destacadas en Mesoamérica se encuentran los sistemas calendáricos. En el caso de Oaxaca, formas transfiguradas de estos calendarios llegan hasta nuestros días entre los pueblos zapotecos, mixtecos, mixes y mazatecos.

Los conocimientos indígenas empíricos y simbólicos adquiridos históricamente a través del uso de los mismos medioambientes han contribuido a su supervivencia, y con ellos le han legado a la humanidad un patrimonio que bien puede contribuir al desarrollo sostenible de la biodiversidad y de los ecosistemas. No obstante, las formas de apropiación simbólica y medioambiental del territorio se ven fuertemente afectadas por el deterioro y la transformación del medio debidos a múltiples factores, entre ellos: la economía de mercado y la consecuente falta de control de los actores sobre los usos de los diferentes medioambientes, la expansión de los cultivos transgénicos sobre los nativos y, de manera principal, los megaproyectos de desarrollo ${ }^{13}$ y las industrias extractivas de recursos del suelo y del subsuelo.

\section{Algunas de las Problemáticas Actuales en Torno a los Territorios Indígenas}

Más allá de los factores mencionados y de muchos otros no mencionados, quiero recoger dos problemáticas que afectan actualmente la integridad de los territorios indígenas en México: una de ellas es la legislación nacional sobre derechos y cultura indígena y la otra la legislación agraria.

La reforma del Artículo 2 de la Constitución Nacional, en la Ley Federal sobre Derechos y Cultura Indígena aprobada por el Congreso en 2001, ha significado un retroceso en cuanto al estatus otorgado a los indígenas, y un espaldarazo a los proyectos autonómicos de las organizaciones etnopolíticas, ya que no son reconocidos como Entidades de "derecho público" con capacidad de autogestión integral, sino como Entidades de "interés público". Esto es, para ser asistidas por el estado, tal como muestran los párrafos del Apartado $\mathrm{B}$ relativos a los impulsos, apoyos y mejoras que la Federación, los estados y los Municipios deben 
dar a las comunidades indígenas en relación con salubridad, educación, cultura, vivienda, economía.

Por otra parte la reforma, aunque se refiere a los pueblos y comunidades indígenas y acepta la definición de pueblo dada por la Organización Internacional del Trabajo (OIT), en casi todos los párrafos menciona solo a las comunidades indígenas, y es ambigua en el reconocimiento de pueblo como sujeto colectivo de derechos. En cuanto a las tierras ocupadas por indígenas solo se refiere a ellas en los términos del Artículo 27 de la Constitución Nacional, sin tomar en consideración el factor étnico, de acuerdo con la forma de tenencia de la tierra establecida por el estado. La tierra, hasta 1992, podía ser de posesión ejidal o comunal y de propiedad privada, pero no de posesión o propiedad étnica; esto es que estas formas de ordenamiento territorial no están pensadas para incorporar a todo un pueblo indígena o vastos sectores de él. En la actualidad el estado no reconoce territorios indígenas, y puede intervenir sobre los recursos del suelo (aguas, bosques) y del subsuelo de las tierras entregadas a los indígenas en usufructo. Aunque les otorga un uso preferente sobre los recursos se reserva aquellos que corresponden a "áreas estratégicas" (Art. 2, A. V.), en las que lleva a cabo grandes proyectos de desarrollo de interés nacional (hidráulicos, turísticos, de minería, entre otros).

La legislación nacional es renuente a considerar a los indígenas como Pueblos con derecho a Territorios y prefiere referirse a ellos como campesinos con derecho a tierras. Esta situación tiene sus antecedentes en la legislación agraria nacional que, como indica Durand (1988), se orientó solo en relación con las demandas campesinas y desconoció las reivindicaciones étnicas. Así, al imponer sus propias categorías de derecho y de distribución del espacio desde comienzos del siglo XX, el derecho agrario ha fragmentado los etnoterritorios en ejidos, tierras comunales y privadas. Ya en el presente, y a pesar de ser signatario de convenios internacionales favorables al reconocimiento y respeto por los derechos territoriales de los pueblos indígenas, el estado solo les reconoce derechos individuales y limitados.

Un breve antecedente debe preceder a la segunda problemática. Como resultado de la revolución social de 1910, la Constitución Nacional de 1917 procedió a la reforma agraria e incluyó el reparto de tierras en el Artículo 27, mismo que se realizó entre 1915 y 1992. Las tierras fueron repartidas en forma de ejidos a las comunidades que habían sido expropiadas por las plantaciones monocultoras o que no tenían títulos primordiales coloniales, o en forma de posesiones comunales a los pueblos que no habían sido expropiados o poseían dichos títulos. La temprana reforma agraria garantizó la posesión inalienable de la tierra a las "corporaciones civiles" (rancherías, pueblos, tribus, etc.), como consideraban legalmente a los pueblos indígenas (Art. 27), y prohibió su venta, pero siempre la conservó como propiedad del estado ${ }^{14}$. En 1991, 100 millones de hectáreas habían sido repartidas entre 3,5 millones de ejidatarios y comuneros (Warman 2002).

En 1992 tuvo lugar una nueva reforma del Artículo 27 de la Constitución Nacional, conocida popularmente como "contrarreforma agraria", concebida como parte de un programa de modernización neoliberal del campo, que creó las condiciones jurídicas para la privatización de las tierras ejidales y comunales y dio por terminada la distribución de tierra de la reforma agraria. Para ello se creó el Programa PROCEDE, con el propósito de "regularizar" la tenencia de la tierra, definir derechos de propiedad de ejidos y comunidades, y dotarlos de títulos de propiedad individuales de solares urbanos, parcelas de labor y tierras del común, usadas estas últimas para pastoreo, forestación, recolección y caza. De Ita (2003) señala que el PROCEDE comenzó el proceso de certificación de tierras en 1998 y en un año incorporó el 34,3\% de todas las existentes en el país, más de la mitad de las cuales son indígenas. Para el 2006 habían sido certificados y titulados como propiedad el 92\% de los ejidos y comunidades agrarias del país (FANAR 2007).

En Oaxaca el Programa PROCEDE y el Fondo Nacional de Apoyo a Núcleos Agrarios sin regularizar (FANAR), que le sucedió, fueron denunciados recientemente por indígenas zapotecos, mixes y mixtecos de 15 comunidades por ser "instrumentos de la política agraria federal para facilitar la privatización de las tierras y los recursos naturales... y allanar el camino a empresas transnacionales, principalmente mineras ${ }^{15}$ " (Vélez 2011) ${ }^{16}$. Cabe enfatizar que el FANAR se ocupa de los casos de comunidades agrarias indígenas conscientes de sus derechos territoriales y renuentes a aceptar la certificación agraria.

Es entonces que a partir de 1992 la tierra campesina indígena fue legalmente inserta en el mercado de tierras, como punto clave para la 
modernización del campo y la inversión privada nacional y extranjera, en tanto que para los indígenas vender la tierra significa perder los derechos sobre el territorio histórico que los identifica como pueblo originario. Perder la base que sustenta su reproducción como grupo humano, su cosmovisión y prácticas rituales, perder el eje a partir del que se construyen las identidades étnicas.

\section{Epílogo}

En este artículo he intentado presentar una panorámica de algunos -a mi entender los principales- de los aspectos de la territorialidad indígena relacionados con su profundidad histórica y sus vivencias y problemáticas contemporáneas, mostrando principalmente la intrínseca relación entre territorialidad y cultura que torna único y singular a cada uno de los constructos territoriales elaborados por cada pueblo indígena. De esta forma, los diferentes etnoterritorios de los indígenas en toda América son en sí mismos evidencias de su honda temporalidad y creatividad cultural. Siendo así, es de esperar que el conocimiento etnológico y antropológico pueda contribuir en las tareas de reconocimiento y legalización de los etnoterritorios, tanto para la retroalimentación sistematizada de sus conocimientos a los propios indígenas, como para la flexibilización de ideas y acciones de los estados nacionales en torno al valor positivo de la pluriculturalidad.

Agradecimientos: Agradezco a los colegas y amigos Viviana Manríquez y Luis Eugenio Campos.

\section{Referencias Citadas}

Abbot, J., R. Chambers, Ch. Dunn, T. Harris, E. de Merode, G. Porter, J. Townsend y D. Weiner 1998. Participatory GIS: Opportunity or oxymoron? Participatory Learning and Action Notes 33:27-33.

Altman, I. y M. Chemers 1980. Culture and Environment. Ed. Brooks/Cole, Pubs. Company, California.

Arvelo, N. y K. Conn 1995. The Ye'kuana self-demarcation process. Cultural Survival Quarterly 18(4):37-51.

Asamblea General de las Naciones Unidas 2007. Declaración de las Naciones Unidas sobre los Derechos de los Pueblos Indígenas. Publicado por las Naciones Unidas.

Aveni, A. 1991. Mapping the Ritual Landscape: Debt payment to Tlaloc during the month of Atlacahualo. To Change Place. Aztec Ceremonial Landscapes, editado por D. Carrasco, pp. 201-227. Colorado University Press, Colorado.

Barabas, A. 1997. La aparición de la Virgen en Oaxaca, México. Una interpretación sobre la multivocalidad del milagro. THULE. Rivista italiana di studi americanistici 2/3:29-47.

- - - (coord.) 2003-2004. Diálogos con el Territorio. Simbolizaciones sobre el Espacio en las Culturas Indígenas de México. 4 volúmenes, Col. Etnografía de México, Serie Ensayos. CONACULTA-INAH, México.

- - - 2003a. Introducción: una mirada etnográfica sobre los territorios simbólicos indígenas. Diálogos con el Territorio. Simbolizaciones sobre el Espacio en las Culturas Indígenas de México, coordinado por A. Barabas, pp. 15-36, Col. Etnografía de México, Serie Ensayos. CONACULTA-INAH, México.

- - - 2003b. Etnoterritorialidad Sagrada en Oaxaca. Diálogos con el Territorio. Simbolizaciones sobre el Espacio en las Culturas Indígenas de México, coordinado por A. Barabas vol. I, pp. 37-120, Col. Etnografía de México, Serie Ensayos. CONACULTA- INAH, México.
- - - 2003c. La Ética del Don en Oaxaca. Los sistemas indígenas de reciprocidad. La Comunidad sin Límites, coordinado por S. Millán y J. Valle, pp. 39-63, Col. Etnografía de México, Serie Ensayos. CONACULTA-INAH, México.

- - - 2006. Dones, Dueños y Santos: Ensayos sobre Religiones en Oaxaca. Editorial Porrúa / Instituto Nacional de Antropología e Historia, México.

Boege, E. 2008. El Patrimonio Biocultural de los Pueblos Indígenas de México. INAH-Comisión Nacional para el desarrollo de los pueblos indígenas (CDI), México.

Carmagnani, M. 1988. El Regreso de los Dioses. FCE, México.

Casey, E. 1996. How to get from space to place in a fairly short stretch of time: Phenomenological prolegomena. Senses of Place, editado por S. Feld y K.H. Basso, pp. 13-52. School of American Research Press, Santa Fe, Nuevo México.

Chapin, M., Z. Lamb y B. Threlkeld 2005. Mapping indigenous lands, Annual Review of Anthropology 34:619-638.

Clarac, J. 2005. El 'mito total': razones de su vigencia entre los indígenas y campesinos de Mérida, Venezuela. Boletín Antropológico 63:57-75, Caracas.

Constitución Política de Los Estados Unidos Mexicanos 2001. Artículo 2, Folio 8283, México.

De Ita, A. 2003. México: impactos del PROCEDE en los conflictos agrarios y la concentración de la tierra. Centro de Estudios para el Cambio en el Campo Mexicano-CECCAM, México.

Durand, C. 1988. Derecho Nacional, Derechos Indios y Derecho Consuetudinario Indígena. Universidad Autónoma de Chapingo-UAM, México.

Eliade, M. 1967. Lo Sagrado y lo Profano. Guadarrama, Madrid.

Ericksen, G. 1980. The Territorial Experience. Human Ecology as Symbolic Interaction. University of Texas Press, Texas. 
Escalera, J. 1999. Territorio, límites, fronteras: construcción social del espacio e identificación colectiva. Globalización, Fronteras Culturales y Politicas y Ciudadanía. VIII Congreso de Antropología, coordinado por J.J. Pujadas Muñoz, E. Martín Díaz y J. Pais de Brito, pp. 99-110, Asociación Galega de Antropoloxía Federación de Asociaciones de Antropología del Estado Español, Santiago de Compostela.

Feld, S. y K.H. Basso (eds.) 1996. Senses of Place. School of American Research Press, Santa Fe, Nuevo México.

Giménez, G. 1978. Cultura Popular y Religión en el Anáhuac. Centro de Estudios Ecuménicos, México.

- - - 1999. Territorio, Cultura e Identidades. La región sociocultural. Estudios sobre las Culturas Contemporáneas. Revista de investigación y análisis Epoca II, V(9):15-39.

- - - 2001. Cultura, Territorio y migraciones. Aproximaciones teóricas. Sociedad Mexicana de Antropología, Zacatecas, México. Manuscrito en posesión del autor.

Giraldo, N. 2010. Camino en espiral. Territorio sagrado y autoridades tradicionales en la comunidad indígena Iku de la Sierra nevada de Santa Marta, Colombia. Revista Pueblos y Fronteras digital.pp. 2-24.

Gómez, M. 2009. La reforma del estado y la pluralidad jurídica. Una mirada a través de las controversias indígenas: Recuento mexicano. Políticas de reconocimiento del pluralismo jurídico y el derecho indígena en América Latina. Manuscrito en posesión de la autora.

Gupta, A. y J. Ferguson 1992. Beyond culture: Space, identity and the politics of difference. Cultural Anthropology 7:1-22.

Herlihy, P. 2003. Participatory research mapping of indigenous lands in Darién, Panamá. Human Organization 62:315-331.

Hirsch, E. y M. O'Hanlon 1995. Landscape: Between Place and Space. The Anthropology of Landscape. Perspectives on Place and Space, editado por E. Hirsch y M. O'Hanlon, pp. 245-270, Clarendon Press, Oxford.

Jansen, M. 1998. La fuerza de los cuatro vientos. Los manuscritos 20 y 21 del Fonds Mexicain. Journal de la Société des Américanistes 84(2):125.161.

Johnson, B.D. 1997. The Use of Geographic Information Systems (GIS) by First Nations. School of Community and Regional Planning, University of British Columbia, Vancouver.

Jolivet, M.J. (ed.) 2000. Logiques identitaires, logiques territoriales. Cahiers des Sciences Humaines. Nouvelle serie 14, Francia.

López Austin, A. 1984. Cuerpo Humano e Ideología. Las Concepciones de los Antiguos Nahuas. UNAM, México.

- - - 1994. Tamoanchan y Tlalocan. FCE, México.

López Austin, A. y L. López Luján 2009. Monte SagradoTemplo Mayor. INAH-UNAM (IIA), México.

Masferrer, E., L. Báez, E.Brenis, N.Barranco, M.Salazar, T.García, G.Montoya, L. Trejo e I. Pérez 2004. Espacios, Territorios y Santuarios en las comunidades indígenas de Puebla. Diálogos con el Territorio. Simbolizaciones sobre el Espacio en las Culturas Indígenas de México, coordinado por A. Barabas, Vol. II, pp. 37-100. Col. Ensayos, Serie Etnografía de los Pueblos Indígenas de México. INAH-CONACULTA, México.
Massey, D. 2005. For Space. SAGE, London.

Myers, F. 1986. The Dreaming: Time and Space. Pintupi Country, Pintupi Self Sentiment. Place and Politics Among Western Desert Aborigines, ed. F. Myers, Smithsonian Institution Press, Washington, D.C.

Orozco, F. y S. Villela 2003. Geografía sagrada en la Montaña de Guerrero. Diálogos Con el Territorio. Simbolizaciones sobre el Espacio en las Culturas Indígenas de México, coordinado por A. Barabas, Vol. I, pp. 125-192, Col. Ensayos, Serie Etnografía de los Pueblos Indígenas de México. INAH-CONACULTA, México.

Prat, J. 1989. Los Santuarios Marianos en Cataluña. La Religiosidad Popular III. Hermandades, Romerías y Santuarios, coordinado por C. Álvarez Santaló, M.J. Buxó Rey y S. Rodríguez Becerra, pp. 223-247. Ed. Anthropos, Barcelona.

Quintal, E.F., J.R. Bastarrachea, F. Briceño, M. Medina, B. Repetto, L. Rejón y M. Rosales 2003. U Lu'Umil Maaya Wiiniko'ob: La tierra de los mayas. Diálogos Con el Territorio. Simbolizaciones sobre el Espacio en las Culturas Indígenas de México, coordinado por A. Barabas, Vol. I, pp. 273-359. Col. Ensayos, Serie Etnografía de los Pueblos Indígenas de México. INAH-CONACULTA, México.

Raffestin, C. 1989. Qu'est-ce que c'est le Territoire? Pour une Géographie du Pouvoir, pp. 57-83. Ed. Litec, París.

Rodman, M. 1992. Empowering place: Multilocality and multivocality. American Anthropologist 94:640-655.

Rudolph, J. y R. Thompson 1992. Política Etnoterritorial. Desafíos en las Democracías Occidentales. Ed. Pomares-Corredor, Barcelona.

Sallnow, M. 1987. Pilgrims of the Andes. Regional Cults in Cusco. Smithsonian Institution Press, Washington D.C.

Schama, S. 1995. Landscape and Memory. A.K. Publisher, New York.

Secretaría de la Reforma Agraria 2007. Fondo de Apoyo para los Núcleos Agrarios sin Regularizar (FANAR). Programa Sustantivo, México.

Smith, D.M. 1990. Introduction: the sharing and dividing of geographical space. Shared Space, Divided Space. Essays on Conflict and Territorial Organization, editado por M. Chisholm y D.M. Smith, pp. 12-25, Unwin Hyman, London.

Soja, E. 1985. The spatiality of social life: Towards a Transformative Retheorisation. Social Relations and Spatial Structures, editado por D. Gregory y J. Urry, pp. 79-97. St. Martin Press, New York.

The First AGS Bowman Expedition "México Indígena”. Prototype for Global GIS Place-based Field research. 2007. Department of Geography, Centre of Latin American Studies, University of Kansas, México Indígena KU (presentación en internet).

Toledo, V., J. Caballero y A. Argueta 1978. El uso múltiple de la selva basado en el conocimiento tradicional. Biótica 3(2):103-144.

Toledo, V. y N. Barrera Bassols 2008. La Memoria Biocultural. La Importancia Ecológica de las Sabidurías Tradicionales. Ed. Icaria, Barcelona.

Unión de Organizaciones de la Sierra Juárez, Oaxaca, S.C. (UNOSJO, S.C.) 2009. Press Bulletin from Union of Organizations of the Sierra Juárez de Oaxaca. Oaxaca, México, 14 enero. 
Valcuende del Río, J.M. 1999. Espacio, territorio y comunidad: procesos de identificación y discursos. Globalización, Fronteras Culturales y Políticas y Ciudadanía. VIII Congreso de Antropología, coordinado por J.J. Pujadas Muñoz, E. Martín Díaz y J. Pais de Brito, pp. 217-228, Asociación Galega de Antropoloxía Federación de Asociaciones de Antropología del Estado Español, Santiago de Compostela.

Valdés del Toro, R. 1993. Caminos hacia el centro. Hacia una fenomenología del espacio sagrado. Romarias e Peregrinacións. Actas do Simposio de Antropología, pp. 73-109. Conselho da Cultura Galega, Santiago de Compostela.

Velasco Toro, J. (coord.) 1997. Santuario y Región. Imágenes del Cristo Negro de Otatitlán. Instituto de Investigaciones Histórico-Sociales, Universidad Veracruzana, Xalapa.
- - - 1999. Líneas temáticas para el estudio de los santuarios. Boletín Colegio de Etnólogos y Antropólogos Sociales, \# 2,5-15, México.

Vélez, O. 2011. Programas federales facilitan privatización de tierras, denuncian. Nota periodística. Periódico Noticias, 22 Diciembre, Oaxaca, México.

Warman, A. 2002. El Campo Mexicano en el Siglo XX. FCE, México.

Winter, M. 1985. Los Altos de Oaxaca. Historia de la Agricultura. Época Prehispánica-Siglo XVI, editado por T. Rojas Rabiela y W.T. Sanders, p.p.148-175. INAH, México.

Zent, E.L., S. Zent y L. Marius 2003. Autodemarcando la Tierra: explorando ideas, árboles y caminos Hoti. Boletín Antropológico 59:313-338.

\section{Notas}

1 Es preciso aclarar que durante los años 2001 y 2002 coordiné en todo el país una investigación sobre "Territorialidad, Santuarios y Peregrinaciones", en el contexto del Proyecto Nacional Etnografía de los Pueblos Indígenas de México en el Nuevo Milenio, desarrollado por la Coordinación Nacional de Antropología del Instituto Nacional de Antropología e Historia. El principal de los productos fue la publicación, en 2003 y 2004, de cuatro volúmenes titulados Diálogos con el Territorio. Simbolizaciones sobre el espacio en las culturas indígenas de México, que reúnen conocimiento etnográfico sobre esos temas en la mayor parte de las culturas indígenas de México. Mi aportación como coordinadora nacional y del equipo Oaxaca e investigadora está presentada tanto en la Introducción (Barabas 2003a) a esos volúmenes como en mi propio trabajo "Etnoterritorialidad sagrada en Oaxaca" (Barabas 2003b), y en publicaciones posteriores. Diálogos con el Territorio muestra, entre otros aportes, que los grupos indígenas construyen material y simbólicamente su territorialidad teniendo como referentes su cosmovisión y un medioambiente histórico y de vivencia cotidiana, manifiestos en el fino conocimiento del medio y en los rituales colectivos, tanto los ligados a la naturaleza como las procesiones y peregrinaciones.

2 Oaxaca es el estado mexicano con mayor diversidad étnica, al contar con 16 grupos etnolingüísticos y dos grupos étnicos. Diversas investigaciones etnográficas realizadas desde 1972 me han permitido convivir con los pueblos chinanteco, chatino, mixe, chocholteco, ixcateco, chontal de Oaxaca, zoque, nahua, zapoteco del valle y mixteco de la región alta, y conocer en diferentes visitas a los pueblos huave, amuzgo, cuicateco, triqui, a los demás subgrupos zapotecos y mixtecos y a los afromexicanos, que, junto con los tacuates, pueden ser conceptualizados como grupos étnicos.

3 Algunos de los autores consultados sobre estos temas: Ericksen 1980, Soja 1985, Myers 1986, Carmagnani 1988, Raffestein 1980, Smith 1990, Aveni 1991, Rodman 1992, Gupta y Ferguson 1992, Hirsch y O'Hanlon (eds.) 1995, Schama 1995, Giménez 1999 y 2001, Feld y Basso 1996, Casey 1996, Jolivet 2000.

4 Los ye'kuana de la Amazonia venezolana (Arvelo y Conn 1995) se han valido del conocimiento y uso ritual de sus ancestrales lugares sagrados para elaborar mapas y promover la delimitación legal de sus territorios étnicos. Otro caso interesante es el de los hoti de la Guayana venezolana, quienes invitaron a un grupo de ecólogos humanos que estaban trabajando en la región en proyectos de conservación biocultural para que los ayudaran a autodemarcar su territorio ancestral. Esta labor de etnogeografía autogestionada comenzó a realizarse en 2001, con el objetivo de entregar la información a la Comisión de Demarcación de Hábitats y Territorios Indígenas, creada ese mismo año, encargada de legalizar la demarcación territorial. En 2002 la comunidad hoti preparó "mapas culturales" elaborados colectivamente, para que sirvieran como referencias y dispositivos mnemotécnicos para la colecta de datos de campo. Al final de este proceso obtuvieron un mapa georreferenciado con más de 2000 puntos de coordenadas tomados con GPS elaborado exclusivamente por ellos (Zent et al. 2003).

5 Entre 1990 y 2005 Chapin et al. (2005:625) registraron proyectos de mapeamiento de tierras nativas en: Indonesia, Filipinas, China, India, Nepal, Tailandia, Cambodia, Vietnam, Australia, Nueva Zelanda, Kenya, Camerún, Sudáfrica, Congo y Tanzania. En América Central: Belice, Nicaragua, Honduras y Panamá. En Sudamérica: Venezuela, Brasil, Ecuador, Colombia, Bolivia y Perú.

6 El uso explícito del término "ethnoterritorial" se encuentra en un artículo de Rudolph y Thompson 1985, y el de "política etnoterritorial" en la publicación española como libro, en 1992. Solo vagamente puede establecerse una relación entre el uso del término por parte de estos autores, y el explicitado en estas páginas y mis anteriores trabajos sobre el tema.

7 Dentro de la conceptualización de Eliade (1967:19) los dueños de lugar son hierofanías, es decir, manifestaciones o revelaciones de lo sagrado, que tienen por efecto destacar un lugar del medio circundante y hacerlo cualitativamente diferente.

8 Ver Carmagnani (1988), Prat (1989), Velasco Toro (1999),

9 La distinción no se basa en nivel de convocatoria (local, subregional, regional, nacional, internacional) porque puede ser de cualquier nivel, aun en los santuarios naturales, ni en las devociones que guían a los fieles, ya que estas son 
múltiples y no contradictorias (a las entidades territoriales, a los ancestros, a los ejemplares católicos), y se practican en ambos tipos de santuarios.

10 Los mitos, tal como ha registrado recientemente Clarac en Venezuela (2005), enseñan cómo debe comportarse la humanidad para actuar de acuerdo con la naturaleza y los mandatos divinos acerca de ella. En los grupos de Oaxaca, por ejemplo, encontramos multitud de relatos que muestran la regulación de la caza impuesta por los dueños, los tabúes previos y posteriores, las prescripciones acerca de los animales cazados, y los castigos que esperan a los que no cumplen con esas normatividades; creencias que inciden en la no depredación del medioambiente.

11 La memoria antigua se reproduce hoy en día en rituales comunales, como por ejemplo las ceremonias de petición de lluvias en Petlacala, Guerrero, en la que se remarcan linderos nombrando el círculo de cerros sagrados en torno del pueblo, como pinta el Códice, a pesar del impacto de las congregaciones coloniales, los posteriores reordenamientos de población, y la evangelización, que transformaron las concepciones indígenas de territorialidad y uso del espacio (Orozco y Villela 2003).

12 Sólo quiero mencionar unos ejemplos, de entre los muchos existentes. Uno de ellos es el sistema interétnico de peregrinaciones del Cristo negro que reúne a 34 comunidades de la mixteca de Puebla en ocasión de la Semana Santa y los rituales de pedimento de lluvia (Masferrer et al. 2004). Por otra parte, en Yucatán se han registrado regiones devocionales que abarcan ex cacicazgos mayas prehispánicos, como el de la Cruz de Popox que recorre los cacicazgos de Chakán, Hocabá y Maní, o el recorrido de la Cruz de Condal que comprende los de Ceh Pech, Chakán, Ah Canha y Ah Kinchel (Quintal et al. 2003).

13 Natalia Giraldo (2010) muestra cómo la violación de los lugares sagrados con la construcción de megaproyectos en la Sierra Nevada de Santa Marta, en Colombia, a pesar de la Resolución del Estado en relación con la protección de lugares sagrados indígenas, no solo afectó el equilibrio ecosistémico, sino también el sistema de conocimiento y gobierno propio de los pueblos indígenas serranos iku. Este grupo arhuaco denuncia que el proyecto Puerto Multipropósito afecta un sitio sagrado denominado julkua (madre de los animales), donde hay tres lagunas para "pagamentos" de las enfermedades, muy importante porque es un centro de la cosmovisión y de la territorialidad de los Iku, donde se restablece ritualmente el orden cósmico.

14 Warman (2002) deja claro que las tierras se entregaron en usufructo, pero permanecían como propiedad de la nación así como los recursos de suelo, subsuelo y aguas terrestres y marítimas.

15 La jurista Magdalena Gómez (2009) señala que la reforma a la Ley de minería (2005) ha abierto el territorio nacional a la explotación minera pasando por encima de los derechos reconocidos a los pueblos indígenas en el Convenio 169 y la declaración de la ONU (2007). Recientemente se ha formado la Red Mexicana contra la Minería integrada por organizaciones de Oaxaca, Guerrero, Chiapas y San Luis Potosí, especialmente en contra de la compañía minera canadiense Fortuna Silver Mines que, a través de su filial la compañía minera Cuzcatlán, fue concesionada por SEMARNAT (Secretaría de Medio Ambiente y Recursos Naturales) para la explotación de minerales en regiones de Oaxaca sin consultar a los pueblos indígenas.

16 Las autoridades de una de las comunidades, Santiago Tutla, destacaron que "funcionarios de la Procuraduría Agraria los hostigan para ingresar al FANAR amenazándolos con retirar los beneficios de políticas públicas como PROCAMPO, OPORTUNIDADES y otros Programas federales, en caso de no aceptar" (Vélez 2011). 